\title{
Coping and self-medication in a community sample of junior high school students
}

\author{
Geneviève Bianca V Bédard BSc, Graham J Reid PhD, Patrick J McGrath PhD, Christine T Chambers BSc
}

GBV Bédard, GJ Reid, PJ McGrath, CT Chambers. Coping and self-medication in a community sample of junior high school students.

Pain Res Manage 1997;2(3):151-156.

OBJECTIVE: To examine differences between high and low catastrophizers in terms of pain, self-medication, coping, age and sex.

DESIGN: Data were collected from 651 junior high students. Coping was assessed in response to pain in general. Pain (intensity and frequency) and self-medication were assessed in response to five types of pain: headache, stomach, muscle and/or joint and/or back, ear and/or throat, and menstrual pains.

RESULTS: Catastrophizing groups were formed based on scores from the upper and lower thirds of a catastrophizing scale. The high catastrophizing group had higher levels of pain intensity and frequency for all five types of pain, and self-medicated more for headache, and ear and/or throat pain, compared with the low catastrophizing group. High catastrophizers reported taking over-thecounter (OTC) medication more frequently than low catastrophizers. High catastrophizers used information seeking, problem solving, social support seeking, positive self-statements and externalization more often than low catastrophizers. Low catastrophizers used behavioural and cognitive distraction more often than high catastrophizers. High catastrophizers perceived themselves to have more difficulty in dealing with pain and less control over their emotions when in pain than low catastrophizers. There were no significant differences between high and low catastrophizers in terms of controllability of pain. There was a higher percentage of catastrophizers in grade 9 than in grades 7 or 8 and a higher percentage of girls catastrophizing than boys.
CONCLUSIONS: More frequent use of coping strategies while experiencing greater pain intensity and frequency may reflect catastrophizers' general inability to reduce pain. Greater use of OTC medications by catastrophizers is likely due to their experiences of more frequent and intense pain.

Key Words: Adolescents, Catastrophizing, Coping, Pain, Selfmedication

\section{L'automédication et la faculté d'adaptation dans un échantillon communautaire d'une population de collégiens}

OBJECTIF : Examiner les différences entre les étudiants excessivement inquiets et sujets à la rumination et les étudiants peu inquiets en ce qui concerne la douleur, l'automédication, la faculté d'adaptation, l'âge et le sexe.

MODÈLE : Les données ont été collectées auprès de 651 collégiens. La faculté d'adaptation a été évaluée en réponse à la douleur en général. La douleur (intensité et fréquence) et l'automédication ont été évaluées en réponse à cinq types de douleur : mal de tête, douleurs gastriques, musculaires et/ou articulaires et/ou lombaires, mal d'oreille et/ou de gorge, et douleurs menstruelles.

RÉSULTATS : Les groupes à l'étude ont été formés sur la base des scores provenant du premier et du dernier tiers sur une échelle de l'anxiété. Le groupe excessivement inquiet et sujet à la rumination démontrait des niveaux plus élevés d'intensité et de fréquence de la douleur pour les cinq types de douleur ; l'automédication dans ce groupe était plus importante pour les maux de tête, d'oreille et/ou de gorge comparativement au groupe des collégiens moins inquiets. Les collégiens excessivement inquiets et sujets à la rumination ont rapporté qu'ils prenaient plus souvent des médicaments en vente libre que les collégiens moins inquiets. Les

voir page suivante

Izaak Walton Killam-Grace Health Sciences Centre and Dalhousie University, Halifax, Nova Scotia

Correspondence: Dr Graham J Reid, Toronto Hospital, General Division, Psychology, CW2-329, 200 Elizabeth Street, Toronto, Ontario M5C 2C4.

Telephone 416-340-4800 ext 3249, e-mail gj.reid@utoronto.ca

Received for publication March 13, 1997. Accepted August 4, 1997 
collégiens excessivement inquiets recherchaient plus souvent de l'information, la résolution de problèmes, un soutien social, des affirmations de soi positives et une extériorisation que les collégiens moins inquiets. Ces derniers utilisaient la distraction cognitive et comportementale plus souvent que les individus excessivement inquiets. Les étudiants sujets à la rumination et excessivement inquiets se percevaient comme ayant plus de difficulté à faire face à la douleur et moins de maîtrise sur leurs émotions lorsqu'ils souffraient que les collégiens moins inquiets. Il n'y avait aucune différence significative entre les plus inquiets et les moins inquiets en ce qui concerne la contrôlabilité de la douleur. Le pourcentage de collégiens inquiets et sujets à la rumination était plus élevé en $9^{\mathrm{e}}$ année qu'en $7^{\mathrm{e}}$ ou $8^{\mathrm{e}}$, et les filles étaient plus inquiètes que les garçons.

CONCLUSIONS : Une utilisation plus fréquente de stratégies d'adaptation lorsqu'ils font l'expérience d'une douleur plus intense et plus fréquente peut refléter un manque de capacité générale des individus excessivement inquiets et sujets à la rumination à réduire la douleur. L'utilisation plus fréquente de médicaments en vente libre par les sujets inquiets et sujets à la rumination est probablement due à leur expérience de douleurs plus intenses et plus fréquentes.
$\mathrm{M}$ any adolescents experience pains such as headaches, stomachaches and, in girls, menstrual pains (1). Adolescents use a variety of strategies to cope with pain $(2,3)$. Catastrophizing has been related to higher pain intensity (2). Few studies have examined differences between adolescents who catastrophize and those who do not. Use of medications is one method of coping with pain. Over-the-counter (OTC) medications are commonly used by adults to deal with pain. However, little is known about how adolescents use OTC medication to cope with pain $(4,5)$. This study provides a description of adolescents who catastrophize in terms of pain experiences (intensity and frequency), use of other coping strategies and OTC medication use.

People adopt different coping strategies to deal with stressors. Some strategies are adaptive, while others are not. Use of catastrophizing when coping with pain and other stressors has consistently been related to higher levels of pain, depression $(6,7)$, functional impairment (7) and behavioural problems (8). In a laboratory study examining the relationship between coping and trait anxiety, Brown et al (9) found that children identified as copers reported less anxiety than children who engaged in catastrophizing cognitions. Catastrophizing adults undergoing a cold pressor and an aversive electrodiagnostic medical procedure reported significantly more negative pain-related thoughts, greater emotional distress and greater pain intensity than noncatastrophizers (10). In a study of children undergoing surgery, Bennett-Branson and Craig (11) found that, after controlling for demographic variables (age, sex and operation type), less catastrophizing was related to less postoperative pain and better physical recovery. Treatment studies have shown that adults with chronic lower back pain who are taught cognitive-behavioural coping strategies (eg, muscle relaxation and imagery) reduced their use of catastrophizing, and reported significant reductions in pain intensity and physical impairment (12). The most important factor in poor coping, both in laboratory and clinical pain, appears to be the presence of catastrophizing rather than differences in adaptive coping strategies.

Definitions of catastrophizing have varied, but rumination, magnification and helplessness are common components of these definitions (10). Individuals who catastrophize repeatedly think about the pain and often worry that the pain will get worse or never stop $(7,10,13)$. Catastrophizers also focus on the lack of controllability over the pain and expectations of failure in dealing with pain $(9,11,14)$. The measure of catastrophizing used in the present study assessed worrying and ruminating about pain and helpless cognitions. The question of whether catastrophizing is an active coping strategy, a pain appraisal or automatic irrational thought can be de- bated $(10,15)$. In dealing with negative moods, rumination coping has been seen as reflecting a self-focusing activity that may involve attempts to understand one's moods better, which suggests that rumination in some situations may be purposeful (16). Children and adolescents spontaneously generate both coping and catastrophizing cognitions when asked what they have done in response to painful or stressful situations. This suggests that children may see catastrophizing as something active $(9,11)$. The present study did not attempt to address these issues. Rather, we provide a description of differences in the use of other coping strategies, pain variables (intensity and frequency) and medication use between adolescents who report that they catastrophize when in pain and those who do not.

Children and adolescents are assuming more responsibility for taking medications (5). Despite the existing knowledge about OTCs, no research has examined the relation between coping strategies and self-medication in adolescence. Further, no one has examined the relation between catastrophizing and OTC use.

The present study examined differences in pain, coping, coping appraisals and the level of responsibility for self-medication between junior high school students who frequently use catastrophizing and those who do not. Catastrophizers were expected to report greater pain intensity and frequency. Due to lack of previous research specific predictions for coping appraisals and selfmedication were not warranted. The relationship between age and sex, and catastrophizing was also examined. Brown et al (9) found that effective coping increased with age and that older children use a greater variety of strategies as they grow older. In the present study, older adolescents were expected to use catastrophizing less often than younger adolescents. Sex differences in the catastrophizing literature seem to emerge later during adolescence (17). In the present study, no sex differences were expected.

\section{Participants and procedure}

\section{METHODS}

Adolescents were recruited from three junior high schools in Halifax, Nova Scotia: Oxford Junior High (191 students), Gorsebrook Junior High (259 students) and Cornwallis Junior High (201 students). Participants were from three grades: grades 7 (237 students), 8 (204 students) and 9 (210 students). The purpose of the study was explained to students, and they were given an informed consent letter to take to their parents. Students were given a $\$ 3$ gift certificate from a local fast food restaurant if consent letters were returned. Of 862 letters distributed, $729(84.6 \%)$ were returned. Of the returned letters, $40(5.5 \%)$ parents declined their child's participation. One week after consent letters were distributed, adolescents 
TABLE 1

Differences in coping strategies and appraisals between low and high catastrophizing groups

\begin{tabular}{|c|c|c|c|}
\hline Coping variable & $\begin{array}{l}\text { Low catastrophizing group } \\
(n=239) \\
\text { Mean } \pm \text { SD }\end{array}$ & $\begin{array}{l}\text { High catastrophizing group } \\
\qquad \begin{array}{c}(n=244) \\
\text { Mean } \pm \text { SD }\end{array}\end{array}$ & $t$ value \\
\hline \multicolumn{4}{|l|}{ Coping strategies } \\
\hline Information seeking & $2.0 \pm 0.78$ & $2.4 \pm 0.78$ & $5.30 * * *$ \\
\hline Problem solving & $3.0 \pm 0.85$ & $3.2 \pm 0.76$ & $3.82 * * *$ \\
\hline Seeking social support & $2.4 \pm 0.87$ & $2.7 \pm 0.84$ & $4.39 * * *$ \\
\hline Positive self-statement & $2.6 \pm 0.95$ & $2.9 \pm 0.83$ & $2.95^{* * \dagger}$ \\
\hline Behavioural distraction & $3.3 \pm 0.97$ & $3.1 \pm 0.85$ & $2.28^{* \dagger}$ \\
\hline Cognitive distraction & $3.2 \pm 1.03$ & $3.0 \pm 0.84$ & $3.02 * *{ }^{\dagger}$ \\
\hline Externalization & $1.6 \pm 0.66$ & $2.3 \pm 0.90$ & $8.59 * * *$ \\
\hline \multicolumn{4}{|l|}{ Coping appraisal } \\
\hline Pain controllability ${ }^{\ddagger}$ & $3.3 \pm 0.90$ & $3.3 \pm 0.87$ & 0.12 \\
\hline Emotion controllability ${ }^{\S}$ & $3.3 \pm 2.22$ & $3.0 \pm 0.83$ & $2.14^{*+}$ \\
\hline Difficulty in pain & $2.4 \pm 0.85$ & $3.1 \pm 0.88$ & $9.03 * * *+$ \\
\hline
\end{tabular}

${ }^{*} P<0.05 ;{ }^{* *} P<0.01 ;{ }^{* *} P<0.001 ;{ }^{\dagger}$ Pooled sample t test for groups with unequal variance; ${ }^{\ddagger}$ Perceived control over pain; ${ }^{5}$ Perceived control over emotions when in pain; "Perceived difficulty in dealing with pain. $n$ Number of students

completed a series of questionnaires during a class period. Thirtyfive students had agreed to participate but were absent during the testing period, and data from three students were excluded. Six hundred fifty-one students (89.3\% students with parental consent) participated in the study, almost all of whom completed the Pain Coping Questionnaire (648 students). The average age of the adolescents was $13.0 \pm 0.93$ years (mean $\pm \mathrm{SD}$ ); $46.2 \%$ were male (301 students).

\section{Questionnaires}

Demographics: Participants completed a basic demographic sheet (ie, age, date of birth, sex and grade).

Pain coping questionnaire: Participants indicated how often they used each of 39 coping strategies ( $1=$ never, $5=$ very often $)$ in response to the statement, "When I am hurt or in pain for a few hours or days, I...". Participants were instructed to think of pains such as headaches, stomachaches, bad muscle pulls, pain in joints (elbow or knee), back pain, earaches or, for women, menstrual pains.

The Pain Coping Questionnaire (PCQ) assesses eight different coping strategies that comprise three types of coping: approach coping, which refers to direct attempts to deal with pain and the use of active methods to regulate feelings when in pain (ie, information seeking, problem solving, social support seeking and positive selfstatements); distraction, which refers to attempts to disengage from the stressor (ie, behavioural or cognitive distraction); and emotionfocused avoidance, which refers to the free expression of emotions (ie, internalizing and/or catastrophizing, or externalizing). The eight coping subscales were formed by averaging items. Items for the catastrophizing subscale are: "Worry that I will always be in pain", "Keep thinking about how much it hurts", "Think that nothing helps", "Think that the pain will never stop" and "Worry too much about the pain". Internal consistencies (Cronbach's alpha) range from 0.78 to 0.86 for children's self-reported coping and 0.70 to 0.91 for parent ratings on the eight subscales (2). Internal consis- tencies for the eight coping subscales in the present study ranged from 0.74 to 0.84 . The PCQ has a stable factor structure in studies with healthy children and adolescents, and children with recurrent pain (arthritis and headache) (2). Child and adolescent ratings on the PCQ are related to parent ratings as well as measures of emotional distress and pain intensity $(2,18)$.

Coping appraisal: Using a 5-point scale ( $1=$ never, 5 = very often $)$, participants rated how often they felt they could do something to change their pain (ie, pain controllability) and their emotions when they were in pain (ie, emotion controllability). Participants also rated how hard $(5=$ really hard $)$ or easy $(1=$ really easy $)$ they felt it was for them to deal with pain (ie, difficulty in dealing with pain) (2).

Pain: Participants rated how often (frequency) and how intensely (intensity) they had experienced each of five pains in the last three months: headache, stomach, ear and/or throat, muscle and/or joint and/or back and, for women, menstrual pains. Usual intensity was assessed for each type of pain using a scale of 0 (no pain) to 10 (worst possible pain). Pain frequency was assessed using a 6-point scale $(1=$ never, $2=$ one to three times, $3=$ four to six times, $4=$ seven to 15 times, $5=16$ to 30 times and $6=31$ or more).

Medication: Participants indicated how often they did each of seven behaviours ( $1=$ never, $5=$ very often $)$ during the last three months. The seven behaviours were things that adolescents who take medications for their pains might do by themselves without checking with an adult first, eg, "I decided when I needed to take medication for my headache pain without checking with an adult first". Only adolescents who reported taking an OTC medication completed these questions. Responses to the seven items were averaged to yield a self-medication score for each type of pain. Internal consistencies for the self-medication variables were high: headache (Cronbach's alpha $=0.91)$, stomach pain $(\alpha=0.92)$, ear and/or throat pain $(\alpha=0.93)$, muscle and/or joint and/or back pain $(\alpha=0.92)$, and menstrual pain $(\alpha=0.93)$. Participants also rated how intense the 


\begin{tabular}{|c|c|c|c|c|c|}
\hline \multirow[b]{2}{*}{ Pain variable } & \multicolumn{2}{|c|}{ Low catastrophizing group } & \multicolumn{2}{|c|}{ High catastrophizing group } & \multirow[b]{2}{*}{ Statistic } \\
\hline & Mean \pm SD & $\mathbf{n}$ & Mean \pm SD & $\mathbf{n}$ & \\
\hline \multicolumn{6}{|l|}{ Headache pain } \\
\hline Frequency $^{+}$ & $1.6 \pm 1.10$ & 239 & $2.0 \pm 1.26$ & 244 & $\mathrm{z}=3.4^{* * *}$ \\
\hline Intensity ${ }^{\ddagger}$ & $4.2 \pm 2.34$ & 239 & $5.1 \pm 2.30$ & 244 & $t(481)=4.2^{* * *}$ \\
\hline \multicolumn{6}{|l|}{ Stomach pain } \\
\hline Frequency $^{\dagger}$ & $1.2 \pm 1.06$ & 239 & $1.6 \pm 1.17$ & 242 & $\mathrm{z}=4.1^{* * *}$ \\
\hline Intensity ${ }^{\ddagger}$ & $3.4 \pm 2.70$ & 239 & $4.6 \pm 2.73$ & 241 & $t(478)=5.0^{* * *}$ \\
\hline \multicolumn{6}{|c|}{ Ear and/or throat pain } \\
\hline Frequency $^{\dagger}$ & $1.0 \pm 0.98$ & 237 & $1.4 \pm 1.11$ & 241 & $z=4.1^{* * *}$ \\
\hline Intensity ${ }^{\ddagger}$ & $3.2 \pm 2.91$ & 237 & $4.5 \pm 2.88$ & 241 & $t(476)=5.0^{* * *}$ \\
\hline \multicolumn{6}{|c|}{ Muscle and/or joint and/or back pain } \\
\hline Frequency ${ }^{\dagger}$ & $1.7 \pm 1.33$ & 233 & $1.9 \pm 1.39$ & 240 & $z=2.2^{*}$ \\
\hline Intensity ${ }^{\ddagger}$ & $4.1 \pm 2.89$ & 233 & $5.16 \pm 2.99$ & 240 & $t(471)=3.9^{* * *}$ \\
\hline \multicolumn{6}{|l|}{ Menstrual pain } \\
\hline Frequency $^{\dagger}$ & $0.8 \pm 1.0$ & 94 & $1.2 \pm 1.27$ & 131 & $z=2.7^{* *}$ \\
\hline Intensity ${ }^{\neq}$ & $2.6 \pm 3.15$ & 94 & $4.3 \pm 3.76$ & 131 & $t(218)=3.8^{\S}$ \\
\hline
\end{tabular}

Independent sample t tests were used to test group differences in the intensity variable, and the z transformation of Mann-Whitney $U$ was used to test group differences in the frequency of medication use. ${ }^{*} P<0.05 ;{ }^{* *} P<0.01 ;{ }^{* * *} P<0.001 ;{ }^{\dagger}$ Frequency of pain over the previous three months; ${ }^{*} A v e r a g e$

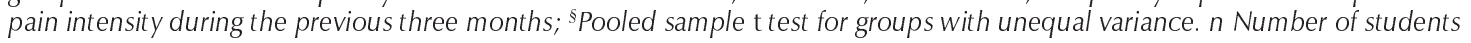

pain had to be before they decided to take medication for each pain by using a 10 -point scale $(0=$ no pain, $10=$ worst possible pain $)$; the approximate percentage of times they took medication for each pain by using a 5 -point scale $(0 \%$ to $24 \%, 25 \%$ to $49 \%, 50 \%$ to $74 \%$, $75 \%$ to $99 \%, 100 \%$ ); and how old they were when they first started taking medication for pain without checking with an adult first (19).

\section{RESULTS}

Two groups were formed based on the catastrophizing scale: upper third (above 2.20, 244 students) and lower third (below 1.60, 239 students). The remaining 165 students (25.5\%) whose scores ranged from 1.60 to 2.20 were not included in the analyses.

A significant sex difference between high and low catastrophizers was found using $\chi^{2}$ analysis, $\left(\chi^{2}[1]=13.53, \mathrm{P}<0.001\right)$. There was a significant effect for grade $\left(\chi^{2}[2]=13.29, \mathrm{P}<0.001\right)$. The proportion of high catastrophizers in grade $9(40.2 \%)$ was significantly higher than in grades $8(28.7 \%)$ and $7(31.1 \%)$.

Table 1 presents differences between high and low catastrophizers in other coping strategies and appraisal variables. High catastrophizers used information seeking, problem solving, social support seeking, positive self-statements and externalization more frequently than low catastrophizers. Compared with high catastrophizers, low catastrophizers used behavioural and cognitive distraction more frequently, reported less difficulty dealing with pain and found it easier to control their emotions when in pain. There were no group differences in terms of pain controllability.

Table 2 presents differences between high and low catastrophizing groups in pain intensity and frequency for all five pains. High catastrophizers reported experiencing all five types of pain more frequently and more intensively than low catastrophizers.

Table 3 presents differences between high and low catastrophiz- ers in medication use for five types of pains. For both headache, and ear and/or throat pains, high catastrophizers reported selfmedicating in general more than low catastrophizers. High catastrophizers took OTC medications more often for their pain than low catastrophizers for all five types of pain. High catastrophizers waited until their pain was at a higher intensity before taking an OTC medication compared with low catastrophizers, but statistically significant group differences were found only for headache and menstrual pains. There were no significant group differences in the age at which adolescents reported that they first began self-medicating.

\section{DISCUSSION}

High catastrophizers reported experiencing headache, stomach, ear and/or throat, muscle and/or joint and/or back, and menstrual pain more intensely and more frequently than low catastrophizers. These results are consistent with previous studies on headache, fibromyalgia, chronic lower back pain and neck pain $(6,7,11,20)$. Children who use catastrophizing frequently express and ruminate on negative emotions. This may enhance the affective components of pain (21) and lead to higher pain intensities. However, frequently experiencing pain of high intensity is distressing and may lead children to use catastrophizing. Because the present study used a correlational design, the direction of the relation between catastrophizing use and pain cannot be determined.

High catastrophizers used information seeking, problem solving, social support seeking, positive self-statements and externalization more frequently than low catastrophizers. However, use of these coping strategies did not result in pain reduction. High catastrophizers used cognitive and behavioural distraction less frequently than low catastrophizers. Ruminating and expressing negative emotions likely decreases children's capacity to engage in distraction strate- 
TABLE 3

Differences in self-medication for five types of pain between low and high catastrophizing groups

\begin{tabular}{|c|c|c|c|c|c|}
\hline \multirow[b]{2}{*}{ Medication variable } & \multicolumn{2}{|c|}{ Low catastrophizing group } & \multicolumn{2}{|c|}{ High catastrophizing group } & \multirow[b]{2}{*}{ Statistic } \\
\hline & Mean \pm SD & $\mathbf{n}$ & Mean $\pm \mathrm{SD}$ & $\mathbf{n}$ & \\
\hline \multicolumn{6}{|l|}{ Headache } \\
\hline Self-medication ${ }^{+}$ & $1.9 \pm 0.94$ & 154 & $2.4 \pm 1.08$ & 166 & $t(318)=4.7^{* * *}$ \\
\hline Percentage $^{\ddagger}$ & $1.6 \pm 1.56$ & 239 & $1.9 \pm 1.60$ & 244 & $z=2.0^{*}$ \\
\hline Intensity medication ${ }^{\S}$ & $5.1 \pm 1.94$ & 164 & $5.6 \pm 1.81$ & 184 & $t(346)=2.5^{*}$ \\
\hline Age at first medication $\pi$ & $11.2 \pm 1.37$ & 84 & $11.4 \pm 1.53$ & 133 & $t(215)=1.4$ \\
\hline \multicolumn{6}{|l|}{ Stomach pain } \\
\hline Self-medication $^{+}$ & $1.9 \pm 0.93$ & 51 & $2.2 \pm 1.06$ & 73 & $t(122)=1.9$ \\
\hline Percentage $^{\ddagger}$ & $0.5 \pm 1.05$ & 239 & $0.9 \pm 1.35$ & 242 & $z=2.8^{*}$ \\
\hline Intensity medication ${ }^{\S}$ & $4.8 \pm 2.11$ & 77 & $5.4 \pm 1.96$ & 107 & $t(182)=1.9$ \\
\hline Age at first medication" & $11.5 \pm 1.45$ & 42 & $11.4 \pm 1.71$ & 68 & $t(108)=0.3$ \\
\hline \multicolumn{6}{|l|}{ Ear/throat pain } \\
\hline Self-medication $^{+}$ & $1.7 \pm 0.92$ & 42 & $2.3 \pm 1.18$ & 64 & $t(104)=2.9 * *$ \\
\hline Percentage $^{\ddagger}$ & $0.7 \pm 1.25$ & 237 & $1.2 \pm 1.48$ & 241 & $z=4.6^{* * *}$ \\
\hline Intensity medication ${ }^{\S}$ & $5.3 \pm 2.25$ & 87 & $5.6 \pm 2.07$ & 131 & $t(216)=0.9$ \\
\hline Age at first medication $\pi$ & $10.8 \pm 1.63$ & 37 & $11.3 \pm 1.51$ & 79 & $t(114)=1.6$ \\
\hline \multicolumn{6}{|l|}{ Muscle/joint/back pain } \\
\hline Self-medication ${ }^{\dagger}$ & $2.0 \pm 0.92$ & 44 & $2.2 \pm 0.96$ & 68 & $t(110)=0.8$ \\
\hline Percentage $^{\ddagger}$ & $0.5 \pm 0.96$ & 233 & $0.8 \pm 1.24$ & 240 & $z=3.6^{* *}$ \\
\hline Intensity medication ${ }^{\S}$ & $6.0 \pm 2.23$ & 68 & $6.2 \pm 2.29$ & 92 & $t(158)=0.7$ \\
\hline Age at first medication & $11.2 \pm 2.18$ & 40 & $11.5 \pm 2.22$ & 60 & $t(98)=0.8$ \\
\hline \multicolumn{6}{|l|}{ Menstrual pain } \\
\hline Self-medication ${ }^{+}$ & $2.8 \pm 1.27$ & 26 & $2.8 \pm 1.30$ & 54 & $t(78)=0.8$ \\
\hline Percentage $^{\ddagger}$ & $0.7 \pm 1.28$ & 94 & $1.3 \pm 1.70$ & 131 & $z=2.9 *$ \\
\hline Intensity medication ${ }^{\S}$ & $5.0 \pm 2.02$ & 28 & $6.1 \pm 2.33$ & 64 & $t(90)=2.1^{*}$ \\
\hline Age at first medication & $12.1 \pm 0.97$ & 22 & $12.2 \pm 1.85$ & 49 & $t(69)=0.2$ \\
\hline
\end{tabular}

${ }^{*} P<0.05 ;{ }^{* *} P<0.01 ;{ }^{* *} P<0.001 ;{ }^{\dagger}$ Mean score of the seven self-medication behavioural questions; ${ }^{*}$ Percentage of pains for which participants took medication; ${ }^{8}$ Pain intensity at which participants take medication; Age when participant first started self-medicating for pain. $n$ Number of students

gies (22), which have been shown to be effective means of coping with pain. A study asking children to rate the perceived effectiveness of various coping strategies is needed to test this interpretation. High and low catastrophizers did not differ on their ratings of controllability of pain, but high catastrophizers believed it was harder for them to deal with pain and felt they could do little to change their emotions when in pain. Similarly, Sullivan et al (10) suggested that catastrophizers have an enduring belief about their inability to effectively cope with painful experiences.

High catastrophizers took medication more frequently for all types of pain than low catastrophizers. High catastrophizers also reported experiencing all types of pain more frequently and intensely than low catastrophizers. Thus, more frequent use of OTC medications for pain can be seen as an appropriate effort to manage intense and frequent pain. More frequent OTC medication use by high catastrophizers may also occur because of perceptions of difficulty in coping with pain and less frequent use of distraction strategies. The present study could not determine whether high catastrophizers took medication after other coping efforts failed. A more in-depth diary or interview study is needed to examine the sequence of coping efforts in dealing with pain.
For headache and menstrual (females only) pains, high catastrophizers waited until their pain was at a higher intensity before taking an OTC medication than low catastrophizers. This suggests that high catastrophizers may use OTC medications after other coping strategies have failed. Alternatively, low catastrophizers use OTC medication earlier, perhaps as just one of their coping strategies. Teaching adolescents to use OTC medications when they first experience significant pain (eg, 3 out of 10 on a pain intensity scale) might allow for a test of the relationship between catastrophizing and pain intensity. If catastrophizing decreased when adolescents used medication at low pain intensities, it would provide some support for the notion that high pain intensity leads to catastrophizing rather than catastrophizing leading to higher pain.

Contrary to our hypothesis, more girls were high catastrophizers than boys. Our results contrast with those of studies of children (9), or combined samples of children and adolescents (2). Our results are similar to those from studies of young adults that found that more women than men were catastrophizers and that women tended to adopt a more ruminative expressive orientation toward dealing with stressful situations (10). Girls, particularly after childhood, experience more pain than boys (1). It is unclear if sex differences are a 
reflection of differences in pain intensity or coping strategy use. The fact that sex differences in catastrophizing seem to appear developmentally at the same time (ie, during adolescence) as sex differences in pain suggests that differences in pain may create sex differences in catastrophizing.

As expected, there was a significant effect related to grade level. The number of high catastrophizers in grade 9 was significantly greater than in grades 7 and 8 . Adolescents start experiencing more pain after about the age of 13, and most adolescents are 13 years old in grade 9 (1). Because our high catastrophizing group had higher pain than the low catastrophizing group, the significant effect for grade is likely due to changes in the frequency of experienced pain.

Future studies should focus on the process and the reasons behind how adolescents decide to self-medicate and the relationship with catastrophizing. It would be interesting to know whether they selfmedicate after other coping strategies have failed. Is self-medication an immediate strategy to deal with pain or are a number of coping strategies used together with self-medication? Equally important would be to examine the relationship among pain, coping and medication use over time, perhaps using diaries. Does higher pain frequency and intensity lead to an increase in medication use and higher catastrophizing or does poor coping lead to higher pain frequency and intensity, and then later on to OTC medication use? An intervention trial in which enhancing coping and medication use are systematically altered is needed to examine causal relations among pain, coping and medication use.

ACKNOWLEDGEMENTS: This project was supported by a research grant from the Izaak Walton Killam-Grace Health Centre, Halifax, Nova Scotia. GJ Reid was supported by an Izaak Walton Killam Children's Hospital Foundation Postdoctoral Fellowship and by an unrestricted research grant from Bristol-Myers Squibb awarded to PJ McGrath at the time this study was conducted. The authors thank Elizabeth Currie for her assistance with this study. Thanks are extended to all members of the Pediatric Pain Research Laboratory at Dalhousie University, Halifax, Nova Scotia and the IWK-Grace Hospital, Halifax, Nova Scotia. Further thanks to the students and staff at Gorsebrook, Cornwallis and Oxford Junior High Schools, Halifax, Nova Scotia for participating in the study.

\section{REFERENCES}

1. Goodman JE, McGrath PJ. The epidemiology of pain in children and adolescents: A Review. Pain 1991;46:247-64.

2. Reid GJ, Gilbert CA, McGrath PJ, Chipuer HM, Ellerton M, Ritchie JA. Development of a pediatric pain coping checklist. Presented at the Third International Symposium on Pediatric Pain, Philadelphia, June 1994.

3. McGrath PJ, Unruh AM. Pain in Children and Adolescents. Amsterdam: Elsevier, 1987.

4. Tse MHW, Chung JTN, Munro JGC. Self-medication among secondary school pupils in Hong Kong: A descriptive study. Family Practice 1989:6:303-6.

5. Rudolf MCJ, Alario AJ, Youth B, Riggs S. Self-medication in childhood: Observations at a residential summer camp. Pediatrics 1993;91:1182-4.

6. Sullivan MJL, D'Eon JL. Relation between catastrophizing and depression in chronic pain patients. J Abnorm Psychol 1990;99:260-3.

7. O'Keefe FJ, Brown GK, Wallston KA, Caldwell DS. Coping with rheumatoid arthritis pain: Catastrophizing as a maladaptive strategy. Pain 1989;37:51-6.

8. Causey DL, Dubow EF. Development of a selfreport coping measure for elementary school children. J Clin Child Psychol 1992;21:47-59.

9. Brown JM, O'Keefe J, Sanders SH, Baker B. Developmental changes in children's cognition to stressful and painful situations. J Pediatr Psychol 1986;11:343-57.

10. Sullivan MJL, Bishop SR, Pivik J. The pain catastrophizing scale: Development and validation. Psychol Assess 1995;7:524-32.

11. Bennett-Branson SM, Craig KD. Postoperative pain in children: Developmental and family influences on spontaneous coping strategies. Can J Behav Sci 1993;25:355-83.

12. Turner JA, Clancy S. Strategies for coping with chronic low back pain: Relationship to pain and disability. Pain 1986;24:355-62.

13. Rosenstiel AK, Keefe FJ. The use of coping strategies in chronic low back pain patients: Relationship to patient characteristics and current adjustment. Pain 1983;17:33-44.

14. Heyneman NE, Fremouw WJ, Gano D, Kirkland F, Heiden L. Individual differences and the effectiveness of different coping strategies for pain. Cogn Ther Res 1990;14:63-77.

15. Jensen MP, Turner JA, Romano JM, Karoly P. Coping with chronic pain: A critical review of the literature. Pain 1991;47:249-83.

16. Nolen-Hoeksema S. Responses to depression and their effects on the duration of depressive episodes. J Abnorm Psychol 1991;100:569-82.

17. Knapp LG, Stark LJ, Kurkjian JA, Spirito A. Assessing coping in children and adolescents: Research and practice. Educ Psychol Rev 1991;3:309-4.

18. Reid GJ, Chambers CT, McGrath PJ, Finley GA. Coping with pain and surgery: Children's and parent's perspectives. Int J Behav Med. (In press)

19. Chambers CT, Reid GJ, McGrath PJ, Finley GA. Over-the-counter medication for pain among adolescents. Arch Pediatr Adolesc Med 1997;151:449-55.

20. Turk DC, Rudy TE. Cognitive factors and persistent pain: A glimpse into Pandora's box. Cogn Ther Res 1992;16:99-122.

21. Melzack R, Wall PD. Pain mechanisms: A new theory. Science 1965;150:971-9.

22. Eccleston $\mathrm{C}$. The attentional control of pain: Methodological and theoretical concerns. Pain 1995;63:3-10. 


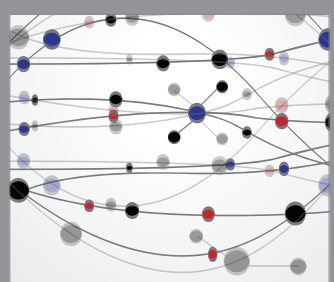

The Scientific World Journal
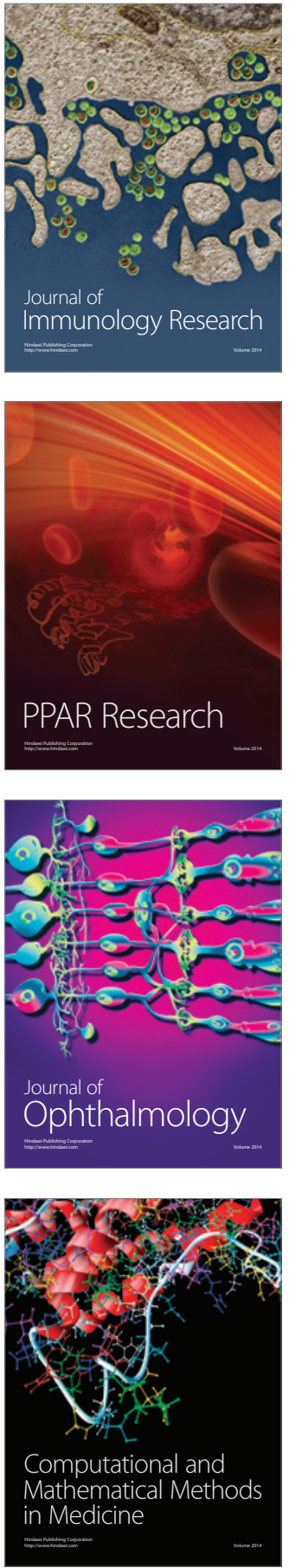

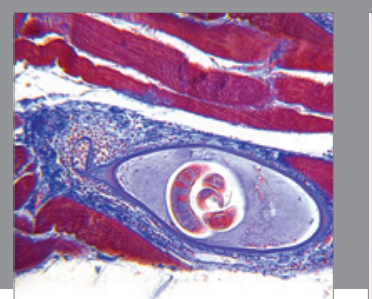

Gastroenterology Research and Practice

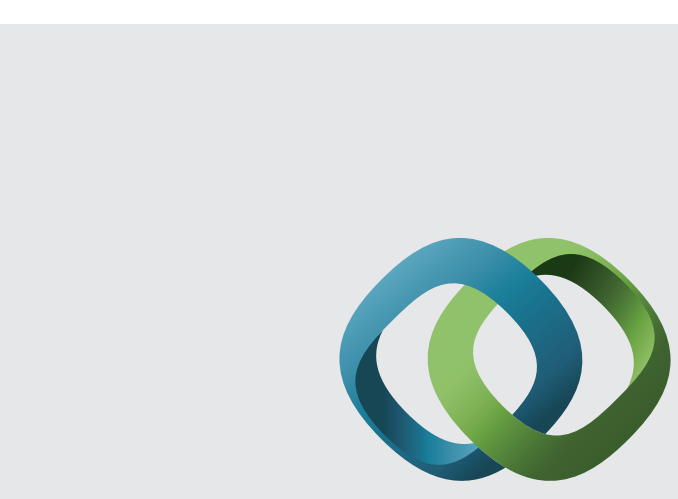

\section{Hindawi}

Submit your manuscripts at

http://www.hindawi.com
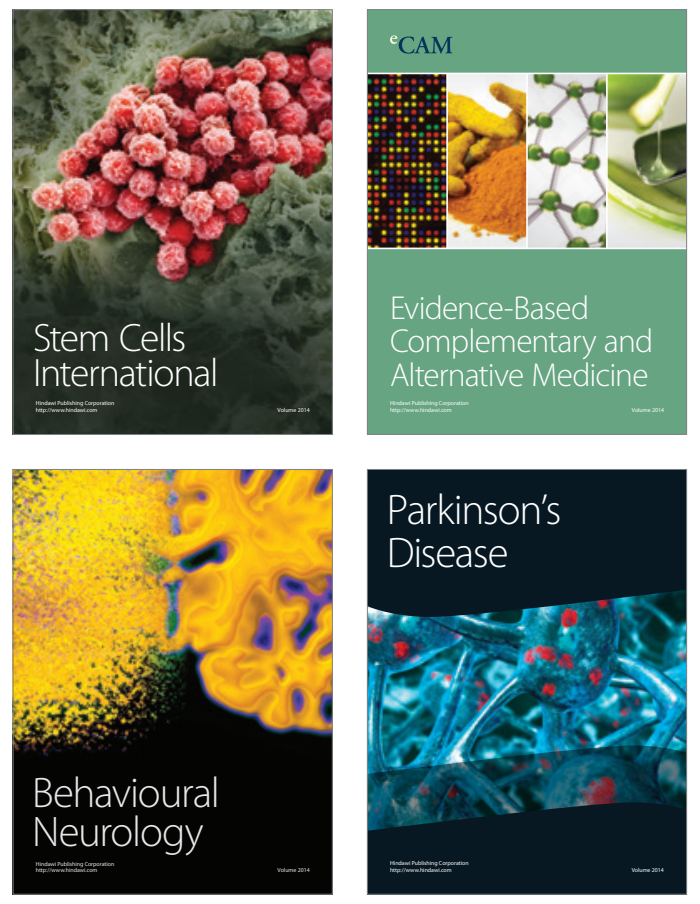
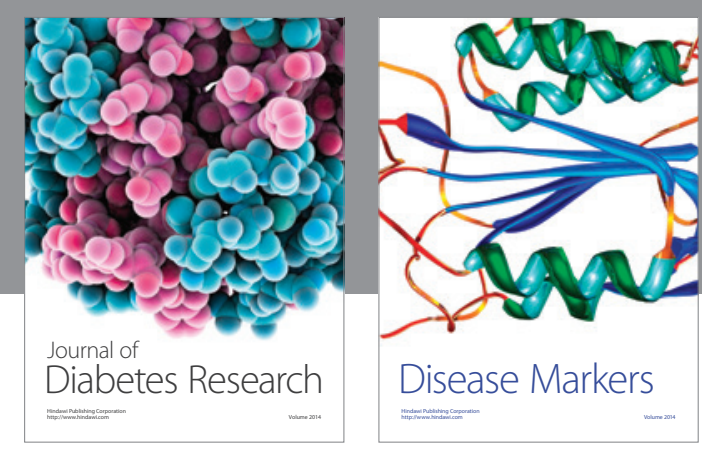

Disease Markers
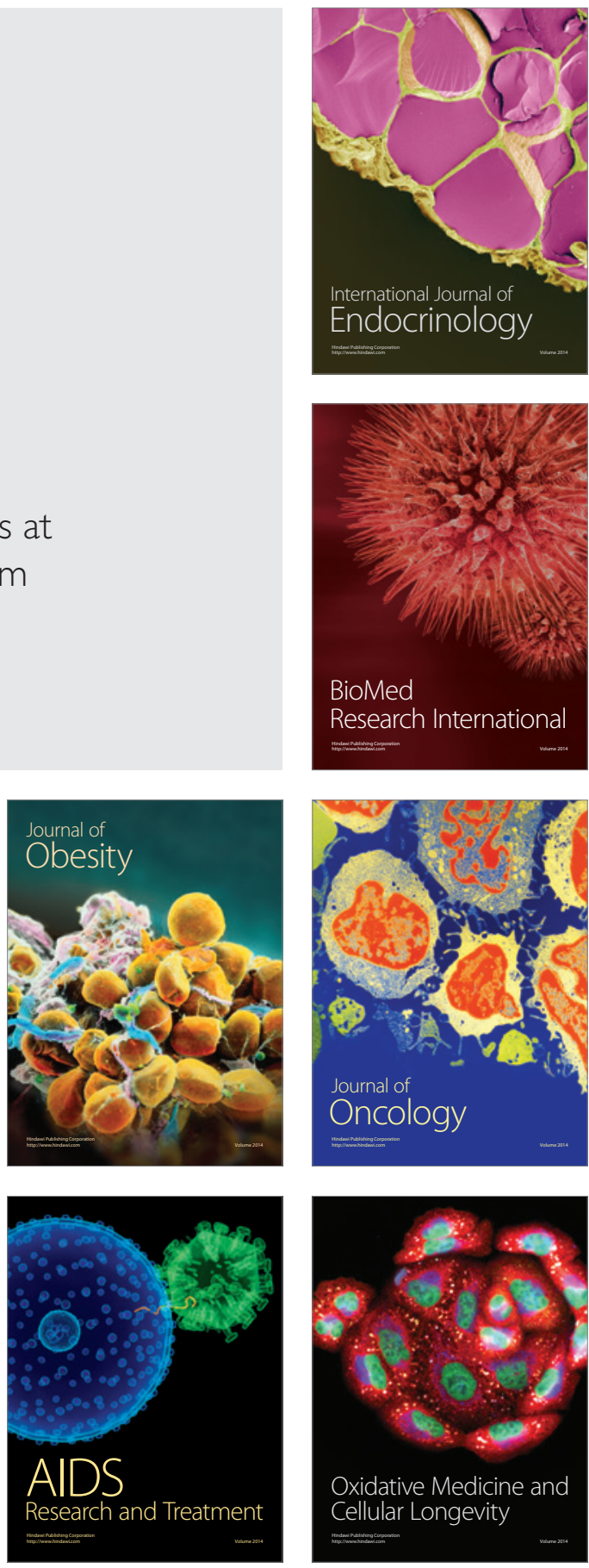